\title{
Variables Associated with Glomerular Hyperfiltration in Fabry Disease Patients
}

\author{
Fernando Perretta (iD) ${ }^{1,}$, Norberto Antongiovanni ${ }^{2}$ and Sebastian Jaurretche $(\mathbb{D})^{3,4}$ \\ ${ }^{1}$ Intensive Care Unit, Dr. Enrique Erill Hospital, Escobar City, State of Buenos Aires, Argentina \\ ${ }^{2}$ Lysosomal Diseases Infusion Center, Nephrology Institute, Pergamino City, State of Buenos Aires, Argentina \\ ${ }^{3}$ Department of Kidney and Kidney-Pancreas Transplantation, Sanatorio Parque, Rosario City, State of Santa Fe, Argentina \\ ${ }^{4}$ School of Medicine, Italian University Institute, Rosario City, State of Santa Fe, Argentina \\ "Corresponding author: Intensive Care Unit, Dr. Enrique Erill Hospital, Escobar City, State of Buenos Aires, Argentina. Email: fjperretta@hotmail.com
}

Received 2020 June 08; Accepted 2020 June 28.

\begin{abstract}
Background: Fabry disease is a genetic disorder caused by the deficiency of the lysosomal $\alpha$-galactosidase A enzyme. This failure generates the storage of globotriaosylceramide in different cells with a progressive multi-organ involvement.

Objectives: To report the prevalence of glomerular hyperfiltration in Fabry disease patients and the association with clinical variables.

Methods: Adult patients ( $\geq 18$ years) at the moment of FD diagnosis were evaluated. The variables studied were: central and peripheral nervous system compromise, presence of arterial hypertension, cardiac arrhythmia, left ventricular hypertrophy, albuminuria/proteinuria, cornea verticillata, gastrointestinal involvement, treatment with inhibitors of the renin-angiotensin-aldosterone system, deafness, and presence of angiokeratomas.

Results: Forty-eight adults with Fabry disease (35.9 \pm 11.7 years), 28 women (58.3\%), and 20 men (41.7\%) were analyzed. Nine (18.8\%) patients with glomerular hyperfiltration, including six females and three males (mean age: 28.8 years), were detected. A significant association between and central nervous system $(\mathrm{P}=0.021)$ and peripheral nervous system $(\mathrm{P}=0.001)$ compromise, cardiac arrhythmia $(\mathrm{P}=0.001)$, cornea verticillata $(\mathrm{P}=0.009)$, and gastrointestinal involvement $(\mathrm{P}=0.009)$ was observed. However, no association was found between glomerular hyperfiltration and proteinuria or treatment with inhibitors of the renin-angiotensin-aldosterone system.

Conclusions: This research showed a higher prevalence of glomerular hyperfiltration in the younger group and a significant association between glomerular hyperfiltration and some typical manifestations of classic Fabry patients. Although more studies are needed, it is concluded that other mechanisms than glomerular hyperfiltration, like injury by glycosphingolipids deposit into the filtration barrier, might influence the protein loss in Fabry nephropathy.
\end{abstract}

Keywords: Fabry Disease, Fabry Nephropathy, Globotriaosylceramide, Glomerular Hyperfiltration, Proteinuria

\section{Background}

Fabry disease (FD) is an X-linked disorder of glycosphingolipid catabolism due to absence or deficiency of the lysosomal $\alpha$-galactosidase A activity ( $\alpha$-GalA, EC 3.2.1.22) (1), which causes the storage of complex glycosphingolipids, mostly globotriaosylceramide (GL-3 or Gb3) and globotriaosylsphingosine (Lyso-GL3), in different tissues (usually in the nervous system, heart, and kidneys). While male patients carrying a genetic mutation develop the disease, female FD patients present wide clinical variabilities, because of the random X-inactivation (Lyon hypothesis) (2).

In $\mathrm{FD}$, a classic form more frequent in male patients without enzymatic activity and a milder non-classic form are described. The classic form usually presents typical signs and symptoms of the disease, such as acroparesthesias, abdominal pain, cornea verticillate, and angiokeratomas. Later in life, these patients develop stroke, hypertrophic cardiomyopathy, and renal failure. In the nonclassic or late-onset form, patients are generally less affected, and the manifestations of the disease are usually limited to a single organ, mainly the heart (cardiac variant) or kidneys (kidney variant) (3).

Although FD has been a known pathology for more than 120 years, during the last 20 years, the prognosis has changed because of the availability of enzyme replacement therapy (ERT) (4). FD is pan-ethnic, and its prevalence ranges from 1:40,000 men to 1:117,000 births (5). A recent analysis of some international results of neonatal screen- 
ing has shown a frequency of 1:22,570 men in classic form and 1:1,390 men in non-classic forms, which would position this pathology as the most frequent lysosomal storage disorder (6).

Kidney failure presents with protein loss in urine and progressive renal impairment (1). The development of FD nephropathy resembles diabetic nephropathy, with glomerular hyperfiltration (GHF) as the first stage, contributing to proteinuria and progressive kidney failure (7). GHF has been indicated in different publications, but its prevalence is poorly understood in Fabry patients.

\section{Objectives}

To report the prevalence of glomerular hyperfiltration in Fabry disease patients and its association with clinical variables.

\section{Methods}

Adult patients ( $\geq 18$ years) were evaluated at the moment of FD diagnosis. Plasma $\alpha$-galA activity was measured using the fluorometric method on filter paper at Dr. Chamoles Laboratory (CABA, Argentina), and the genetic test was performed by multiplex ligation-dependent probe amplification (MLPA) and sequencing at Baylor Genetics (Houston, Texas, USA). The glomerular filtration rate (GFR) was estimated by the CKD-EPI formula (8). Estimated GFR over $125 \mathrm{~mL} / \mathrm{min} / 1.73 \mathrm{~m}^{2}$ was considered as GHF (9).

The variables studied were: central nervous system (CNS) compromise, peripheral nervous system (PNS) compromise, presence of arterial hypertension (AHT), cardiac arrhythmia, left ventricular hypertrophy (LVH), albuminuria/proteinuria, cornea verticillata, gastrointestinal involvement, treatment with inhibitors of the renin-angiotensin-aldosterone system (RAAS), deafness, and presence of angiokeratomas.

CNS compromise was determined by clinical stoke history or asymptomatic lesions on brain magnetic resonance (1). PNS compromise was considered in patients suffering from acroparesthesias or in the presence of alterations in quantitative sensory testing (QST) (10).

AHT was defined according to the guidelines of the American College of Cardiology (ACC) and the American Heart Association (AHA) (11). Cardiac arrhythmia was evaluated by the presence of electrophysiological alterations in 12-lead electrocardiogram (ECG) and left ventricular hypertrophy (LVH) by transthoracic echocardiography (1). Septal and left ventricular posterior wall between 6 and $11 \mathrm{~mm}$ were considered to be normal (12). Albuminuria was defined as persistent values $>30 \mathrm{mg} / 24$ hours and proteinuria as persistent values $>300 \mathrm{mg} / 24$ hours (13).
Cornea verticillata was assessed by ophthalmological slit-lamp examination. Gastrointestinal involvement centered on abdominal pain and recurrent diarrhea and nausea without any other cause than $\mathrm{FD}(1)$. Deafness was determined with tonal audiometry and the presence of angiokeratomas by dermatological exam.

\subsection{Data Analysis}

SPSS version 20 (IBM Inc., Chicago, Illinois, USA) was used to perform the analysis. The normal distribution of continuous variables was tested with the use of the Shapiro-Wilk test. Descriptive statistics were presented as mean \pm standard deviation (SD) for continuous variables and percentages for categorical variables. To compare demographic, clinical, and laboratory data, the chi-square or Fisher's exact test, ANOVA, Kruskal-Wallis or independent t-test were used. P value of less than 0.05 was considered statistically significant.

\section{Results}

Forty-eight patients (28 women [58.3\%] and 20 men [41.7\%]) with a confirmed diagnosis of $\mathrm{FD}(35.9 \pm 11.7$ years) were studied. A total of 15 index cases were identified. The $\alpha$-galA activity was low in all male patients and only in $14.3 \%$ of female patients. An overall of 14 GLA gene mutations were found: E398X, L415P, M296V, L106R, R227Q, A292T, c.448.delG, R363H, C382Y, R301Q, D109G, del 3\&4 exons, W81X, and R342X; all of which were pathogenic FD mutations (http://fabry-database.org/mutants). 9/48 patients (18.8\%) with GHF were detected, which included six females and three males (mean age: 28.8 years). The characteristics of the study population are shown in Table 1.

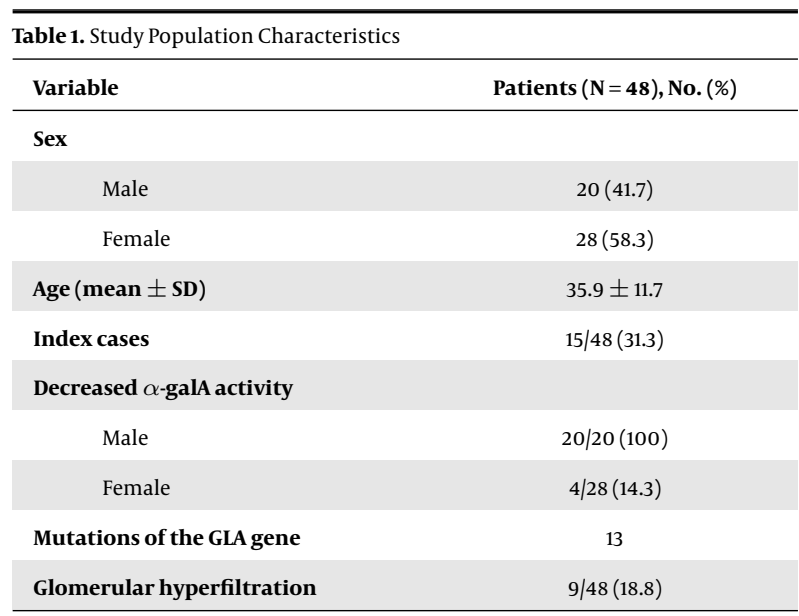

In the first quartile of age, a major prevalence of GHF was evidenced (Figure 1). Figure 2 shows the distribution 
of GHF frequencies by age. A significant association was found between GHF and CNS compromise $(\mathrm{P}=0.021)$, PNS compromise $(\mathrm{P}=0.001)$, cardiac arrhythmia $(\mathrm{P}=0.001)$, cornea verticillata $(\mathrm{P}=0.009)$, and gastrointestinal involvement $(\mathrm{P}=0.009)$. No significant relationship was noted between GHF and proteinuria $(\mathrm{P}=0.859)$, LVH $(\mathrm{P}$ $=0.386)$, AHT $(\mathrm{P}=0.248)$, RAAS inhibitors treatment $(\mathrm{P}=$ $0.248)$, deafness $(P=0.564)$, and the presence of angiokeratomas $(\mathrm{P}=0.386)$. Table 2 shows the frequencies and associations between GHF and the different variables studied.

Table 2. Frequencies and Association Between Glomerular Hyperfiltration and the Different Variables Studied

\begin{tabular}{|c|c|c|c|}
\hline & $\begin{array}{c}\text { FD Patients With } \\
\text { GHF }\end{array}$ & $\begin{array}{c}\text { FD Patients } \\
\text { Without GHF }\end{array}$ & PValue \\
\hline CNS involvement & $2 / 9(22.2 \%)$ & $14 / 39(35.9 \%)$ & $0.021^{\mathrm{a}}$ \\
\hline PNS involvement & $7 / 9(77.8 \%)$ & $29 / 39(74.4 \%)$ & $<0.001^{\mathrm{a}}$ \\
\hline $\begin{array}{l}\text { Cardiac } \\
\text { arrhythmia }\end{array}$ & $0 / 9(0 \%)$ & $6 / 39(15.4 \%)$ & $<0.001^{\mathrm{a}}$ \\
\hline $\begin{array}{l}\text { Cornea } \\
\text { verticillata }\end{array}$ & $3 / 9(33.3 \%)$ & $12 / 39(30.8 \%)$ & $0.009^{\mathrm{a}}$ \\
\hline GI compromise & $1 / 9(11.1 \%)$ & $14 / 39(35.9 \%)$ & $0.009^{\mathrm{a}}$ \\
\hline Proteinuria & $6 / 9(66.7 \%)$ & $33 / 39(84.6 \%)$ & 0.859 \\
\hline LVH & $1 / 9(11.1 \%)$ & $20 / 39(51.3 \%)$ & 0.386 \\
\hline AHT & 1/9 (11.1\%) & $19 / 39(48.7 \%)$ & 0.248 \\
\hline $\begin{array}{l}\text { RAAS inhibitors } \\
\text { treatment }\end{array}$ & $2 / 9(22.2 \%)$ & $18 / 39(46.2 \%)$ & 0.248 \\
\hline Deafness & $2 / 9(22.2 \%)$ & $20 / 39(51.3 \%)$ & 0.564 \\
\hline Angiokeratomas & $2 / 9(22.2 \%)$ & $19 / 39(48.7 \%)$ & 0.386 \\
\hline \multicolumn{4}{|c|}{$\begin{array}{l}\text { Abbreviations: AHT, arterial hypertension; CNS, central nervous system; FD, } \\
\text { Fabry Disease; GHF, glomerular hyperfiltration; GI, gastrointestinal; LVH, } \\
\text { left ventricular hypertrophy; PNS, peripheral nervous system; RAAS, renin- } \\
\text { angiotensin-aldosterone system. } \\
\text { a P values less than } 0.05 \text { were considered statistically significant. }\end{array}$} \\
\hline
\end{tabular}

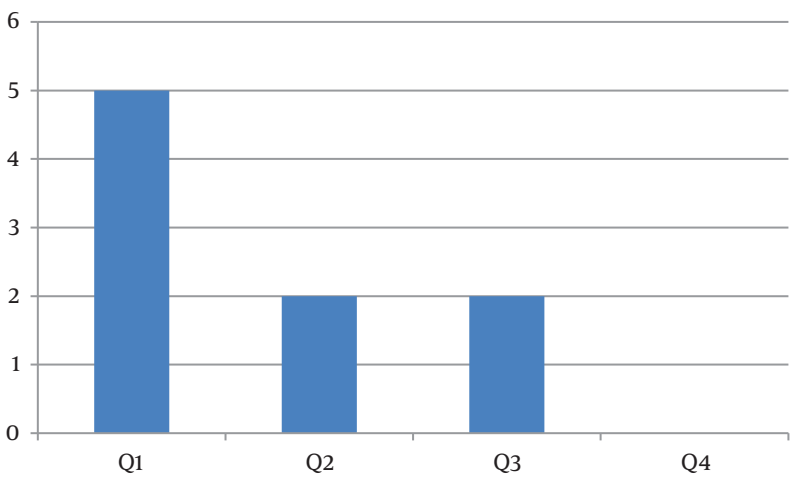

Figure 1. Distribution of glomerular hyperfiltration frequencies by quartiles of age

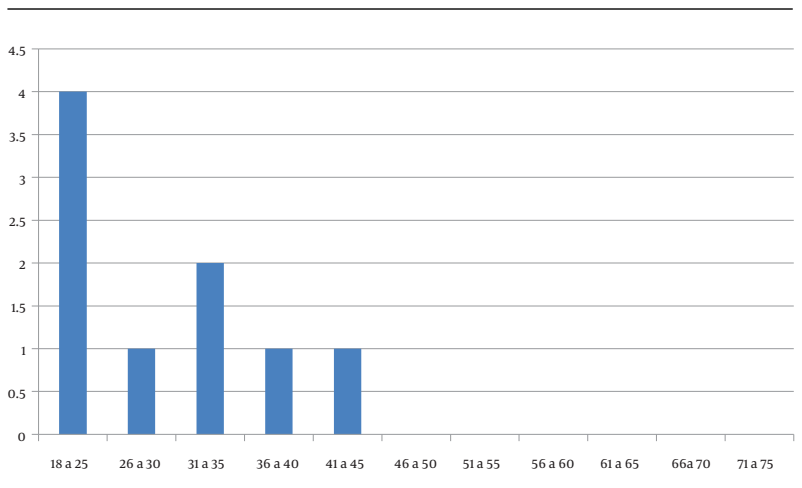

Figure 2. Distribution of glomerular hyperfiltration frequencies by age

\section{Discussion}

Nephropathy is a serious complication of FD patients (14). Fabry nephropathy presents with different severity stages with a similar progression rate to diabetic nephropathy, whereby male patients with the classic and untreated form usually develop end-stage renal disease in their fourth decade of life (9). In general, male patients without specific treatment exhibit three phases of FD nephropathy; the first is characterized by GHF, the second by renal involvement with albuminuria and proteinuria, and in the third phase, patients develop severe renal disease with cardiovascular and neurological compromise (5).

GHF is considered an early phenomenon in the sequence of events ranging from intraglomerular hypertension to albuminuria, and subsequently to the reduction of the glomerular filtration. The factors involved in its physiopathology are multiple and not so well known, and include numerous humoral factors such as nitric oxide, prostaglandins, RAAS, atrial natriuretic peptide, reactive oxygen species, etc. (15). The presence of such pathogenic factors has previously been reported in patients with FD (16).

Unfortunately, there is no simple and precise method to measure renal functionality that is feasible in daily clinical practice. Glomerular filtration can be evaluated using exogenous or endogenous markers. Measurements with exogenous substances as nuclear markers or inulin are the gold standard to calculate renal function in FD patients (17). However, these methods are expensive and time-consuming. Creatinine is the most used endogenous marker. The CKD-EPI formula has demonstrated more accurate GFR measurements than other formulas, especially in the higher ranges (8). This formula has recently been validated and may be useful in FD patients (9).

In the present analysis, we have found low plasma $\alpha$ - 
galA activity in all males and only in $14.3 \%$ of females. The lyonization would be responsible for the high percentage of normal enzyme activity in women of our population. This X-chromosome inactivation impacts the natural history of female patients with $\mathrm{FD}(18,19)$. We have identified GHF in approximately one-fifth of our samples. The detection of a major prevalence of GHF in the first quartile of age is coincident with the natural evolution of Fabry nephropathy in patients without specific treatment. A recent retrospective observational study in Italy showed a similar result with a GHF prevalence of $24 \%$ in a population of $87 \mathrm{FD}$ patients (20).

Clinical manifestations of the classic phenotype have been described before 7 years of age with neuropathic pain crisis in extremities (typically triggered by physical activity, fever, and temperature changes), post-prandial abdominal pain, and frequent diarrhea. Also, dermatological lesions such as angiokeratomas and hypohidrosis may be present before the second decade of life. Later, hearing loss, tinnitus, vertigo, and ocular involvement usually accompany the finding of podocyturia and proteinuria. After the third decade, cardiac manifestations such as arrhythmias, chest pain, LVH, and stroke can occur (21). In this analysis, we observed a significant association between GHF and CNS and PNS compromise, cardiac arrhythmia, cornea verticillate, and gastrointestinal involvement, most of which are manifestations of the classic FD form. No association was found between GHF and proteinuria, LVH, AHT, treatment with RAAS inhibitors, deafness, and the presence of angiokeratomas.

In Argentina, a recent analysis of young patients with classic FD forms and mild or absent nephropathy showed urinary microRNAs suggestive of kidney fibrosis, even in non-albuminuric cases (22). Riccio et al. reported that GHF may be an early marker of renal involvement in FD patients, even before the onset of signs, symptoms, or laboratory changes (20). Although proteinuria can be considered an indirect marker of GHF, there are situations where the urinary protein loss is due to alterations in the glomerular filtration barrier secondary to a glomerular disease rather than a consequence of the GHF per se. Therefore, we can infer that the proteinuria detected in our population would be related to other mechanisms, such as damage in the glomerular filtration barrier produced by the deposition of glycosphingolipids and not by the presence of GHF.

\subsection{Conclusions}

In summary, this research has evidenced a higher prevalence of GHF in the younger group and a significant association between GHF and some clinical symptoms of the classic form. However, there was no association between GHF and proteinuria or RASS inhibitors treatment.
Nowadays, the physiopathology of GHF in Fabry patients is not well known. Even though further research is needed, it is concluded that other mechanisms than glomerular hyperfiltration, like injury by glycosphingolipids deposit into the filtration barrier, might influence the protein loss of Fabry nephropathy.

\section{Acknowledgments}

The authors would like to thank Mrs. Soledad Maidana for the collaboration in the English translation of this research article.

\section{Footnotes}

Authors' Contribution: Study concept and design: F. P.; analysis and interpretation of data: F. P. and S. J.; drafting of the manuscript: F. P.; critical revision of the manuscript: N. A. and S. J.; statistical analysis: S. J.

Conflict of Interests: The authors have no conflicts of interest to declare regarding this article.

Funding/Support: The authors declare no funding.

\section{References}

1. Germain DP. Fabry disease. Orphanet J Rare Dis. 2010;5:30. doi: 10.1186/1750-1172-5-30. [PubMed: 21092187]. [PubMed Central: PMC3009617].

2. Desnick RJ, Allen KY, Desnick SJ, Raman MK, Bernlohr RW, Krivit W. Fabry's disease: enzymatic diagnosis of hemizygotes and heterozygotes: $\alpha$-galactosidase activities in plasma, serum, urine, and leukocytes. J Lab Clin Med.1973;81(2):157-71.

3. Arends M, Wanner C, Hughes D, Mehta A, Oder D, Watkinson OT, et al. Characterization of Classical and Nonclassical Fabry Disease: A Multicenter Study. J Am Soc Nephrol. 2017;28(5):1631-41. doi: 10.1681/ASN.2016090964. [PubMed: 27979989]. [PubMed Central: PMC5407735].

4. Eng CM, Guffon N, Wilcox WR, Germain DP, Lee P, Waldek S, et al. Safety and efficacy of recombinant human alpha-galactosidase A replacement therapy in Fabry's disease. N Engl J Med. 2001;345(1):9-16. doi: 10.1056/NEJM200107053450102. [PubMed: 11439963].

5. Desnick RJ, Ioannou YA, Eng CM. Alpha-Galactosidase A deficiency: Fabry disease. In: Scriver CR, Beaudet AL, Sly WS, Valle D, editors. The metabolic and molecular basis of inherited disease. 8th ed. New York: McGraw-Hill; 2001. p. 3733-74.

6. Matern D, Gavrilov D, Oglesbee D, Raymond K, Rinaldo P, Tortorelli S. Newborn screening for lysosomal storage disorders. Semin Perinatol. 2015;39(3):206-16. doi: 10.1053/j.semperi.2015.03.005. [PubMed: 25891428].

7. Del Pino M, Andres A, Bernabeu AA, de Juan-Rivera J, Fernandez E, de Dios Garcia Diaz J, et al. Fabry Nephropathy: An EvidenceBased Narrative Review. Kidney Blood Press Res. 2018;43(2):406-21. doi: 10.1159/000488121. [PubMed: 29558749].

8. Levey AS, Stevens LA, Schmid CH, Zhang YL, Castro A3, Feldman HI, et al. A new equation to estimate glomerular filtration rate. Ann Intern Med. 2009;150(9):604-12. doi: 10.7326/0003-4819-150-9-20090505000006. [PubMed: 19414839]. [PubMed Central: PMC2763564]. 
9. Rombach SM, Baas MC, ten Berge IJ, Krediet RT, Bemelman FJ, Hollak CE. The value of estimated GFR in comparison to measured GFR for the assessment of renal function in adult patients with Fabry disease. Nephrol Dial Transplant. 2010;25(8):2549-56. doi: 10.1093/ndt/gfq108. [PubMed: 20215390].

10. Politei JM, Durand C, Schenone AB. Small Fiber Neuropathy in Fabry Disease: a Review of Pathophysiology and Treatment. Journal of Inborn Errors of Metabolism and Screening. 2016;4:232640981666135. doi: 10.1177/2326409816661351.

11. Blonsky R, Pohl M, Nally JV, Thomas G. 2017 ACC/AHA hypertension guidelines: Toward tighter control. Cleve Clin J Med. 2018;85(10):771-8. doi: 10.3949/ccjm.85a.18028. [PubMed: 30289752].

12. Lang RM, Bierig M, Devereux RB, Flachskampf FA, Foster E, Pellikka PA, et al. Recommendations for chamber quantification: a report from the American Society of Echocardiography's Guidelines and Standards Committee and the Chamber Quantification Writing Group, developed in conjunction with the European Association of Echocardiography, a branch of the European Society of Cardiology. J Am Soc Echocardiogr. 2005;18(12):1440-63. doi: 10.1016/j.echo.2005.10.005. [PubMed: 16376782].

13. Alegre JR, Alles A, Angerosa M, Bianchi ME, Dorado E, Etchegoyen MC, et al. Documento de Consenso: implicancia de la proteinuria en el diagnóstico y seguimiento de la enfermedad renal crónica. Acta bioquímica clínica latinoamericana. 2013;47(3):613-25.

14. Jaurretche S, Antogiovanni N, Perretta F. Prevalence of chronic kidney disease in fabry disease patients: Multicenter cross sectional study in Argentina. Mol Genet Metab Rep. 2017;12:41-3. doi: 10.1016/j.ymgmr.2017.05.007. [PubMed: 28607873]. [PubMed Central: PMC5443960].

15. Mascheroni CA. Fisiopatología de la hiperfiltración glomerular en la diabetes. Parte 1. Revista de nefrología, diálisis y trasplante. 2014;34(3):130-54.

16. Eikrem O, Skrunes R, Tondel C, Leh S, Houge G, Svarstad E, et al. Pathomechanisms of renal Fabry disease. Cell Tissue Res. 2017;369(1):53-62. doi: 10.1007/s00441-017-2609-9. [PubMed: 28401309].

17. Kleinert J, Lorenz M, Hauser AC, Becherer A, Staudenherz A, Fodinger $M$, et al. Measurement of renal function in patients with Fabry disease. Acta Paediatr Suppl. 2005;94(447):19-23. discussion 9-10. doi: 10.1111/j.1651-2227.2005.tb02105.x. [PubMed: 15895707].

18. Echevarria L, Benistan K, Toussaint A, Dubourg O, Hagege AA, Eladari $\mathrm{D}$, et al. X-chromosome inactivation in female patients with Fabry disease. Clin Genet. 2016;89(1):44-54. doi: 10.1111/cge.12613. [PubMed: 25974833].

19. Perretta F, Antongiovanni N, Jaurretche S. Major Organic Involvement in Women with Fabry Disease in Argentina. ScientificWorldJournal. 2018;2018:6515613. doi: 10.1155/2018/6515613. [PubMed: 29950951]. [PubMed Central: PMC5987241].

20. Riccio E, Sabbatini M, Bruzzese D, Annicchiarico Petruzzelli L, Pellegrino A, Spinelli L, et al. Glomerular Hyperfiltration: An Early Marker of Nephropathy in Fabry Disease. Nephron. 2019;141(1):10-7. doi: 10.1159/000493469. [PubMed: 30466100].

21. Politei JM, Aiziczon D, Aguilar M, Alberton V, Alonso S, Amoreo O. Recomendaciones para el diagnóstico, tratamiento y seguimiento de la enfermedad de fabry en Argentina. Revista Nefrología Argentina. 2018;16(2):1-29.

22. Jaurretche S, Venera G, Antongiovanni N, Perretta F, Perez GR. Urinary Excretion of microRNAs in Young Fabry Disease Patients with Mild or Absent Nephropathy. Open Journal of Nephrology. 2018;8(3):71-83. doi: 10.4236/ojneph.2018.83009. 